\title{
Clearing of the Radioactive Liquid Waste from Oils and Oil Products by UV-Radiation at NPPS
}

\author{
Sergey A. Kulyukhin, Vladimir V. Kulemin, Vladimir B. Krapukhin, Viktor A. Lavrikov, \\ Andrey V. Gordeev, Andrey A. Shiryaev, Alexey A. Bessonov \\ Frumkin's Institute of Physical Chemistry and Electrochemistry, Russian Academy of Sciences, Moscow, Russia \\ Email: Kulyukhin@ipc.rssi.ru
}

Received November 2014

\begin{abstract}
The basic methods of concentration and purification of liquid radioactive waste on the nuclear power plant are distillation and ionic exchange. During vaporization of oil waste products and the fulfilled washing solutions the part of oil passes into a condensate. Clearing of such condensate on ion-exchanged filters results to oiling of ion-exchanged materials and to decrease number of filter cycles. Due to the often regeneration of ion-exchanged filters additional volumes of waste products as the fulfilled reclaiming solutions, washing and loosening waters are formed. The attention of scientists was involved with methods of clearing of water environments from the organic substances, based on deep oxidizing transformations of hydrocarbons into carbonic gas and water. From processes of oxidation of hydrocarbons up to $\mathrm{CO}_{2}$ and $\mathrm{H}_{2} \mathrm{O}$, sold at moderate conditions, our attention has involved photochemical oxidation with the help of UV-radiation.
\end{abstract}

\section{Keywords}

Nuclear Power Plant, Liquid Radioactive Waste, Oil, UV-Radiation

\section{Introduction}

The main methods of concentration and purification of liquid radioactive waste (LRW) at Russian nuclear power plants (NPPs) are distillation and ion exchange. Evaporation of oily waste and the spent washing solutions part of oil goes into the condensate. The purification of this condensate by ion exchange results to oiling filter exchange materials and reduce the number of filtration cycles. Additional quantities of waste in the form of the fulfilled reclaiming solutions, washing and loosening waters are produced by more frequent regeneration of ionexchange filters. According to the technology adopted by the NPP, the condensate was purified from the oil on coal filters or filters downloaded by copolymer of styrene and divinylbenzene. Such purification is not effective and often does not provide the requirements established for the waste water. Therefore was been sought the more efficient methods of oil allocation from aqueous media. Main attention was attracted to the purification of aqueous environments from organic substances, based on the deep oxidative transformations of hydrocarbons in 
carbonic dioxide and water. Processes of hydrocarbons oxidation to $\mathrm{CO}_{2}$ and $\mathrm{H}_{2} \mathrm{O}$, sold under mild conditions, can be distinguished the oxidation by ozone, hydrogen peroxide and etc., electrochemical, electrocatalytic and photochemical oxidation [1]-[5]. Among these will be the last method seems the most promising, because it allows selective using of energy without the addition of certain substances for chemical transformations. In addition, the exclusion of sorbents for cleaning water solutions reduces the amount of solid radioactive waste. This paper deals with the establishment of some cleaning regularities of water solutions, including model and real LRW of Russian Kalinin's NPP, from petroleum oils by photochemical method.

\section{Experimental}

The cleaning effects of temperature and initial oil content were studied. The scheme of set-up for study of the effects of temperature and initial oil content into purification are presented on Figure 1. The set-up consists of thermostat cup 1 with cleaned medium mounted on a magnetic stirrer 2 . The irradiation carried out by a mercury lamp 3 (capacity of a lamp was $220 \mathrm{Wt}$ ). The focusing mirror 4 was used for a more complete using of the lamp. $200 \mathrm{ml}$ of water with certain amount of spindle oil was irradiated. The choice of spindle oil was conditioned due to its wide use as a lubricant. The research was carried out at oil content 8.5 and $17 \mathrm{mg} / \mathrm{dm}^{3}$. Thus air oxygen dissolved in the liquid and entrapped it from surrounding atmosphere while stirring was used for oxidation. The researches of cleaning up oil model solution simulating trap waters of NPP were also conducted. Model solution of trap water contained, g/dm ${ }^{3}$ : NaNO-0.166, $\mathrm{Na}_{2} \mathrm{SO}_{4}-0.074, \mathrm{H}_{3} \mathrm{BO}_{3}-1.576, \mathrm{KNO}_{3}-1.295, \mathrm{NH}_{3}-1.0$, oils- $17 \times$ $10^{-3}$.

The installation with the mercury lamp introduced into solution for practicing water solutions cleaning mode was developed (Figure 2). This set-up included reactor 1, mercury lamp 2 in a quartz glass case 3 and agitator 4. The $1 \mathrm{dm}^{3}$ of solution was irradiated. The purified aqueous solution heated during a mercury lamp irradiation. During process the solution was heated from temperature $25^{\circ} \mathrm{C} \pm 1^{\circ} \mathrm{C}$ to some final temperature.

\section{Results and Discussion}

As follow from Figure 3, the temperature increasing may increase the rate of purification. It is apparently

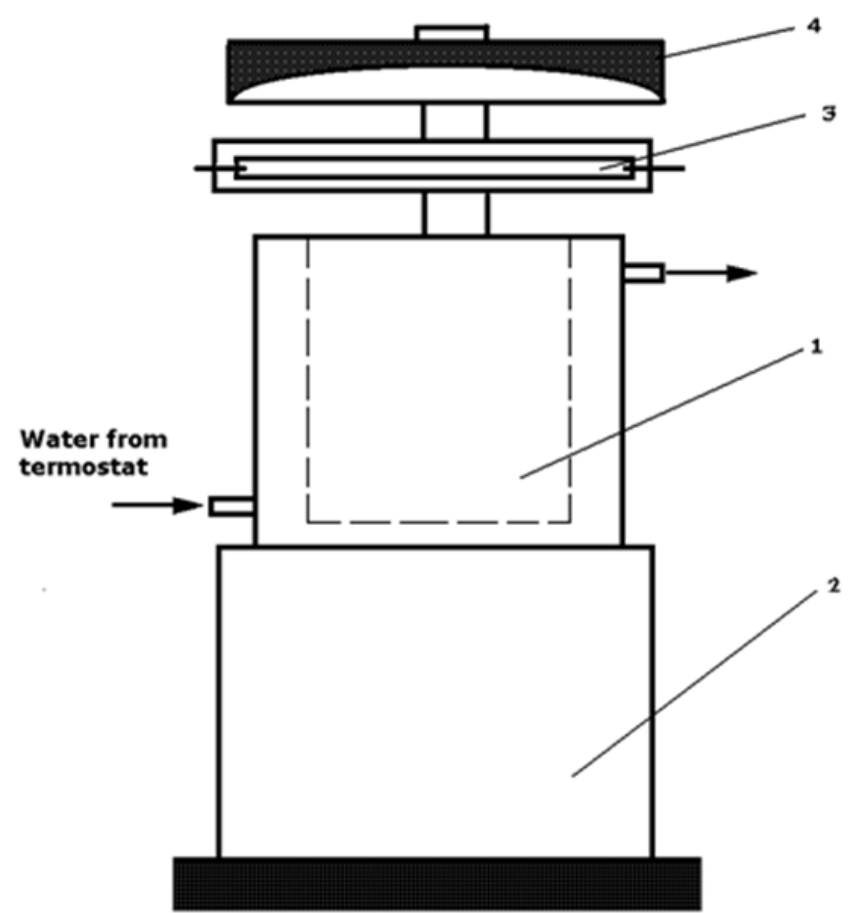

Figure 1. The scheme of set-up for study of the effects of temperature and initial oil content. (1-temperature-controlled glass, 2-magnetic stirrer, 3-high pressure mercury lamp, 4-focusing mirror). 


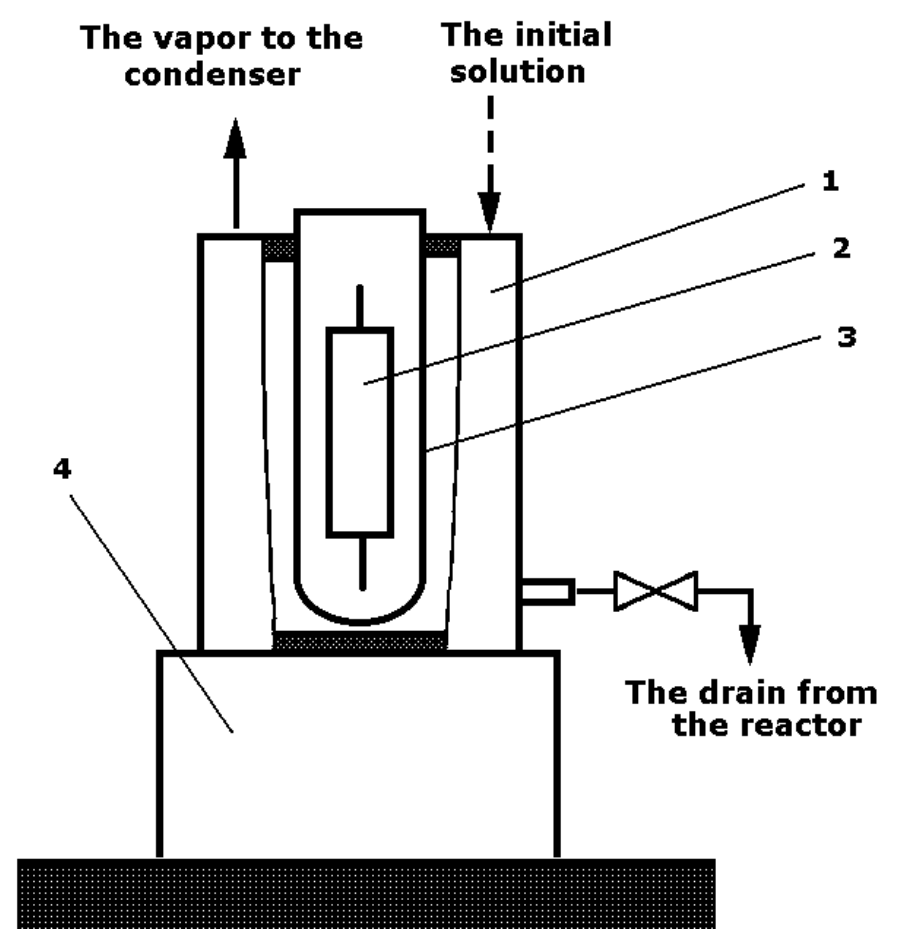

Figure 2. Set-up for testing regimes of cleaning aqueous solution from oils. (1-reactor, 2-pressure mercury lamp, 3-case of quartz glass, 4-magnetic stirrer).

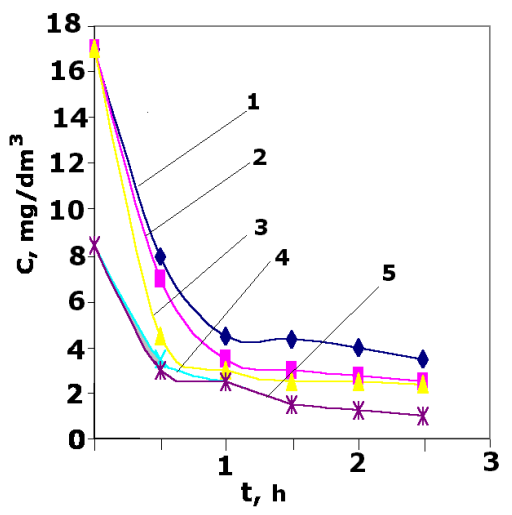

Figure 3. The dependence of the residual oil from the exposure time. (1-the model solution with $\mathrm{C}_{0}=17 \mathrm{mg} / \mathrm{dm}^{3}, \mathrm{~T}=67^{\circ} \mathrm{C}$; 2-oil-water mixture with $\mathrm{C}_{\mathrm{o}}=17 \mathrm{mg} / \mathrm{dm}^{3}, \mathrm{~T}=52^{\circ} \mathrm{C} ; 3$-oil-water mixture with $\mathrm{C}_{\mathrm{o}}=$ $17 \mathrm{mg} / \mathrm{dm}^{3}, \mathrm{~T}=67^{\circ} \mathrm{C}$; 4-oil-water mixture with $\mathrm{C}_{\mathrm{o}}=8.5 \mathrm{mg} / \mathrm{dm}^{3}, \mathrm{~T}=$ $52^{\circ} \mathrm{C}$; 5-oil-water mixture with $\mathrm{C}_{\mathrm{o}}=8.5 \mathrm{mg} / \mathrm{dm}^{3}, \mathrm{~T}=67^{\circ} \mathrm{C}$ ).

explained by the contribution of the secondary "dark" reactions of atmospheric oxygen and the photolysis products of oil. The most sharply reduced oil content for small irradiation time, when the content of the organic phase is large. With increasing initial concentrations of oil in water increases the rate of decomposition organic phase. Thus, if the initial oil concentration of $8.5 \mathrm{mg} / \mathrm{dm}^{3}$ for $0.5 \mathrm{~h}$ at $67.0^{\circ} \mathrm{C} \pm 0.5^{\circ} \mathrm{C}$ its loss is $1.24 \mathrm{mg}$, then the initial concentration of $17 \mathrm{mg} / \mathrm{dm}^{3}$, and the same temperature the loss is equal to $2.52 \mathrm{mg}$, that is almost 2 times more. The oil decomposition rate increasing with increase of the initial amount can be clearly explained, firstly, increasing the probability by collision of UV radiation photons with oil molecules at increasing concentrations, and, secondly, it should be borne in mind that the petroleum oils are composed of substances which absorb UV radiation having a wavelength as $\lambda<200 \mathrm{~nm}$, and with $\lambda>200 \mathrm{~nm}$. For example, aromatic compounds capable 
of absorbing light with $\lambda>200 \mathrm{~nm}$ [6]-[8] are alkanes unlike almost transparent in this area [6] [7] [9] [10].

Compounds, which can absorb UV radiation with $\lambda>200 \mathrm{~nm}$, become excited and probably able to transmit their energy to oxygen molecules or organic substances that are transparent to the radiation of long wave length. Thus, the spectrum of the mercury lamp radiation was expanded. Excited organic molecules react apparently by dark reactions with triplet or singlet oxygen. The data of model solution cleaning are shown in Figure 3. As follow from Figure 3, in this case the cleaning rate is less than the mixture of oil and water is irradiated. It is obviously due to the absorption of the UV radiation by ions presented in the model solution. Table 1 shows the purification of aqueous media from the oil data obtained by introducing mercury lamp defecating directly into the solution (see Figure 2). Due to heating of the solution by the mercury lamp, the energy consumption for conducting the cleaning process was reduced. As seen from Table 1, the energy needed to decompose of the organic phase decreases with increasing initial oil content of the solution. At this rate of reduction of energy consumption, starting from a certain initial amount of oil also begin to decline.

To verify the data obtained on the model solutions, studies have been conducted on waste water of Kalinin' NPP. For check of the data received on model solutions, experiments have been carried out on waste water from the tank of pure condensate, the pump of decontaminated water, and also the tank of trap waters of the Kalinin NPP. Besides mineral oil trap waters contained, Bk/dm ${ }^{3}:{ }^{134} \mathrm{Cs}-4.18 \times 10^{5},{ }^{137} \mathrm{Cs}-6.85 \times 10^{5},{ }^{54} \mathrm{Mn}-23.94 \times 10^{2}$, ${ }^{131} \mathrm{I}-4.07 \times 10^{4},{ }^{60} \mathrm{Co}-7.92 \times 10^{3},{ }^{24} \mathrm{Na}-12.32 \times 10^{3}$, and also $\mathrm{Fe}^{3+}-1.2 \mathrm{mg} / \mathrm{dm}^{3}, \mathrm{Na}^{+}-3.0, \mathrm{~K}^{+}-0.27, \mathrm{H}_{3} \mathrm{BO}_{3}-2.2$ $\mathrm{g} / \mathrm{dm}^{3}$, pH-from 9 up to 12 . Density of a solution was $1.007 \mathrm{~g} / \mathrm{cm}^{3}$. Water from the pump of degassed water and the tank of pure condensate supervised only on the contents of mineral oil. Waste water is purified in a plant similar to that shown in Figure 3. It was irradiated with $1.5-1.8 \mathrm{dm}^{3}$. Experimental data are presented in Table 2, which show that by using photolysis for water from the tank of pure condensate containing the organic matter

Table 1. Experimental data on the purification of water and model solutions from oils by using of a mercury lamp.

\begin{tabular}{|c|c|c|c|c|c|}
\hline Composition of solution & $\begin{array}{l}\text { The final } \\
\text { temperature of } \\
\text { the solution, }{ }^{\circ} \mathrm{C}\end{array}$ & $\begin{array}{l}\text { The exposure } \\
\text { time, min }\end{array}$ & $\begin{array}{l}\text { The oil content after } \\
\text { irradiation, mg }\end{array}$ & $\begin{array}{l}\text { The amount of the } \\
\text { decomposed oil, mg }\end{array}$ & $\begin{array}{c}\text { Amount of } \\
\text { expended } \\
\text { energy, } \\
\text { KWt/mg }\end{array}$ \\
\hline \multirow{3}{*}{$\begin{array}{c}1 \mathrm{dm}^{3} \text { of water }+ \\
0.004 \mathrm{ml} \text { of oil } \\
\left(3.4 \mathrm{mg} / \mathrm{dm}^{3}\right)\end{array}$} & 54.5 & 15 & 0.60 & 2.80 & 0.020 \\
\hline & 85.0 & 30 & 0.46 & 2.94 & 0.037 \\
\hline & 99.5 & 60 & 0.14 & 3.26 & 0.067 \\
\hline \multicolumn{6}{|l|}{$\begin{array}{l}1 \mathrm{dm}^{3} \text { of modeling solution } \\
\text { and oil, } \mathrm{ml}\left(\mathrm{mg} / \mathrm{dm}^{3}\right)\end{array}$} \\
\hline $0.004(3.4)$ & 100 & 60 & 0.17 & 3.23 & 0.068 \\
\hline $0.008(6.8)$ & 100 & 60 & 0.25 & 6.55 & 0.033 \\
\hline $0.008(6.8)$ & 99.5 & 45 & 0.23 & 6.57 & 0.025 \\
\hline $0.020(17)$ & 99.5 & 45 & 0.37 & 16.13 & 0.010 \\
\hline $0.040(34)$ & 99.5 & 60 & 1.71 & 32.29 & 0.007 \\
\hline $0.060(51)$ & 99.5 & 60 & 5.38 & 45.42 & 0.005 \\
\hline
\end{tabular}

Table 2. Experimental data on the purification of the Kalinin's NPP LRW from oils.

\begin{tabular}{|c|c|c|c|c|c|c|c|}
\hline \multirow{2}{*}{ No. } & \multirow{2}{*}{ LRW from } & \multirow{2}{*}{$\begin{array}{l}\text { Time } \\
\text { of the experiment, } \mathrm{h}\end{array}$} & \multicolumn{2}{|c|}{ Temperature, ${ }^{\circ} \mathrm{C}$} & \multicolumn{2}{|c|}{$\begin{array}{l}\text { The concentration of petroleum } \\
\text { products, } \mathrm{mg} / \mathrm{dm}^{3}\end{array}$} & \multirow{2}{*}{$\begin{array}{l}\text { The } \\
\text { coefficient of } \\
\text { purification }\end{array}$} \\
\hline & & & Initial & Final & Initial & Final & \\
\hline 1 & \multirow{5}{*}{$\begin{array}{l}\text { The tank } \\
\text { of pure } \\
\text { condensate }\end{array}$} & 3.00 & 35.0 & 90.0 & 1.10 & 0.20 & 5.5 \\
\hline 2 & & 1.50 & 73.0 & 94.0 & 1.05 & 0.22 & 4.3 \\
\hline 3 & & 1.00 & 72.5 & 92.0 & 2.58 & 0.33 & 7.3 \\
\hline 4 & & 0.50 & 88.0 & 100.0 & 1.06 & 0.78 & 1.4 \\
\hline 5 & & 0.25 & 34.5 & 94.0 & 1.61 & 0.50 & 3.2 \\
\hline 6 & \multirow{2}{*}{$\begin{array}{l}\text { The pump of } \\
\text { degassed water }\end{array}$} & 2.00 & 79.0 & 100.0 & 1.24 & 0.30 & 3.1 \\
\hline 7 & & 2.60 & 79.5 & 100.0 & 3.90 & 0.63 & 6.2 \\
\hline 8 & $\begin{array}{l}\text { The tank of } \\
\text { trap waters }\end{array}$ & 5.00 & 43.0 & 100.0 & 5.80 & 0.95 & 6.1 \\
\hline
\end{tabular}




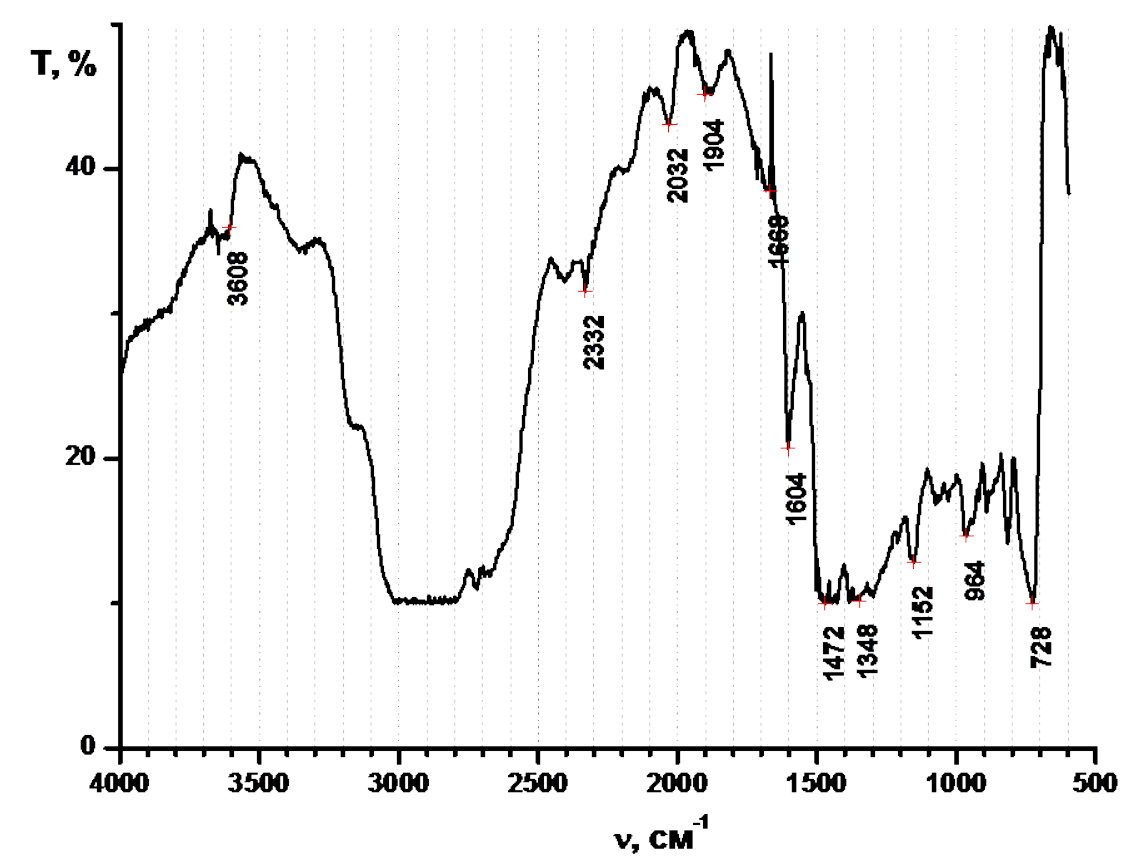

Figure 4. IR spectra of the destruction products of spindle oil under UV radiation.

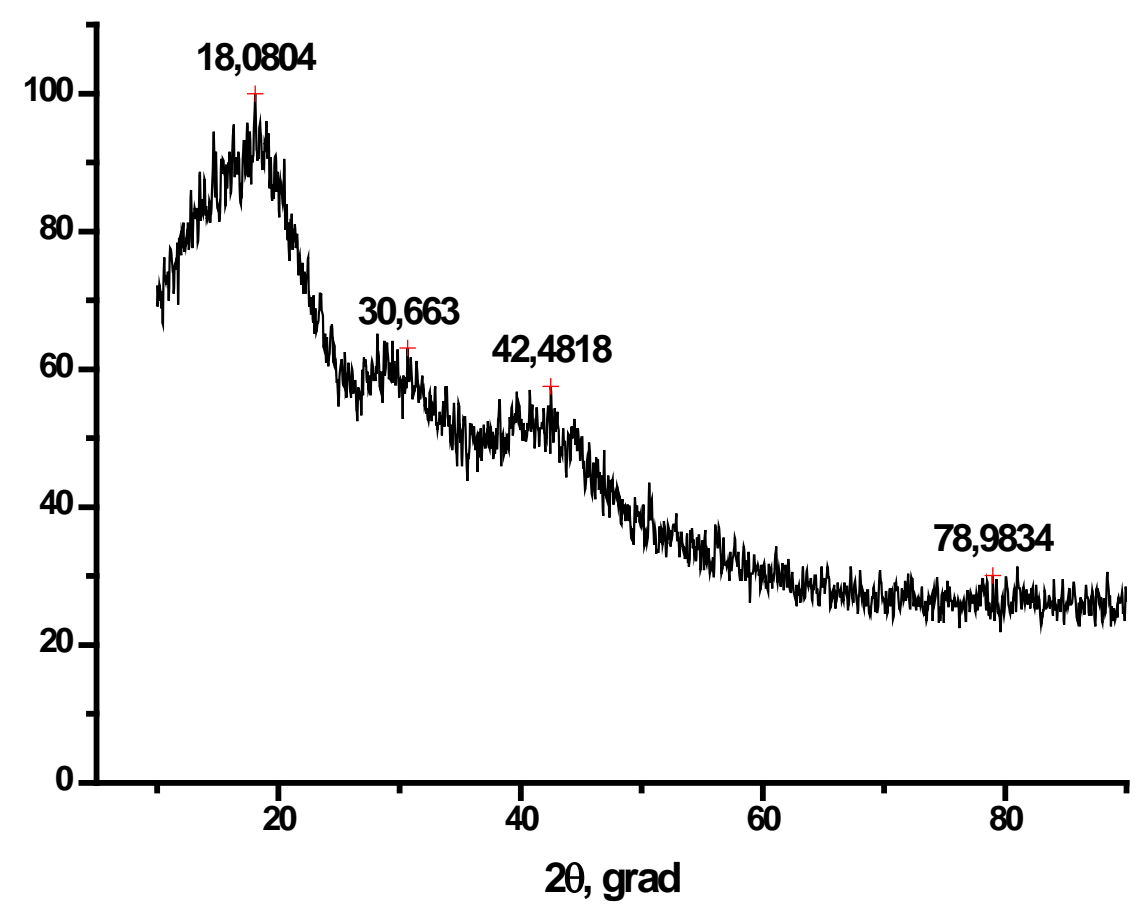

Figure 5. The X-ray diffraction pattern of the destruction products of spindle oil under UV radiation.

of more than $1 \mathrm{mg} / \mathrm{dm}^{3}$ can be purified to a concentration of less than $0.5 \mathrm{mg} / \mathrm{dm}^{3}$, and hence re-use. Degassed water after the evaporator with the initial content of more than $1 \mathrm{mg} / \mathrm{dm}^{3}$ can be purified to a concentration of $0.3-0.6 \mathrm{mg} / \mathrm{dm}^{3}$. Reducing the oil content is beneficial to the subsequent purification with ion-exchange resin. Trap water can be purified from petroleum products to contain less than $1 \mathrm{dm}^{3}$. However, in this case, the exposure time increases significantly compared to purification of water from the pure condensate tank and the pump 
of degassed water. It is consistent with the data shown in Figure 3.

It was of interest for us to study the destruction products of spindle oil under UV radiation. Towards that end we irradiated spindle oil in tantalum boats in air atmosphere, which resulted in formation of a very fine black film. We recorded the IR spectra (Figure 4) and X-ray diffraction pattern (Figure 5) of the film.

Analysis showed that the IR spectra (Figure 4) mainly included bands due to the vibrations of C-H and C-C bonds [11]. On the other hand, a study of the X-ray diffraction pattern showed that it included a set of peaks similar to those theoretically calculated for methenamine in JCPDS-ICDD according to crystallographic data [12]. The chemical formula of methenamine is $\mathrm{C}_{6} \mathrm{H}_{12} \mathrm{~N}_{4}$, and it is characterized by the presence of $\mathrm{N}-\mathrm{C}$ bonds [13]. The appearance of nitrogen bonds in the composition of the destruction products might be due to that the oil, along with hydrocarbon compounds, includes nonhydrocarbon compounds, which can have a respective hydrocarbon skeleton with one, two, and etc. sulfur, oxygen, and nitrogen atoms.

\section{Conclusion}

In conclusion, it should be noted that the removal of oil from aqueous radioactive solutions using UV radiation is a promising method for water purification plant. Method of cleaning oil from aqueous solutions using UV radiation is most convenient for cleaning radioactive condensates. Thus, the research study has demonstrated a good potential of using UV radiation as an effective method to remove hydrocarbon products, including industrial oils, from liquid radioactive waste.

\section{Announcement}

Work is supported by Council about grants of the President of the Russian Federation for the state support of leading scientific schools of the Russian Federation (grant SS-5418.2014.3).

\section{References}

[1] Proskurjakov, V.A. and Shmidt, L.I. (1977) The Purification of Waste Water in Chemical Industry. Chemistry (USSR), Leningrad.

[2] Krasnoborodko, I.G. (1988) The Destructive Purification of Waste Water from Dyes. Chemistry (USSR), Leningrad.

[3] Shevtchenko, A.I., Martchenko, P.V., Taran, P.N. and Lizunov, V.V. (1978) Oxidants in Water Treatment Technology. Naukova dumka (USSR), Kiev.

[4] Orlov, V.A. (1978) Water Ozonolysis. Mir (USSR), Moscow.

[5] Zaitsev, N.K., Krasnii, D.V. and Zimina, G.V. (1999) A Method for Treating Aqueous Fluids Containing Organic Impurities. Russia Patent N 2142915.

[6] Bultrup, J. and Koil, J. (1978) Excited States in Organic Chemistry. Mir (USSR), Moscow.

[7] Stern, K. and Timmons, K. (1974) Electronic Absorption Spectroscopy in Organic Chemistry. Mir (USSR), Moscow.

[8] Kazitsina, L.A. and Kupletskaya, N.B. (1971) Application of the UV, IR and NMR of Organic Chemistry. Vysshaya shkola (USSR), Moscow.

[9] Kalvert, J. and Pits, J. (1968) Photochemistry. Mir (USSR), Moscow.

[10] Sverdlova, O.V. (1973) Electronic Spectra in Organic Chemistry. Chemistry (USSR), Leningrad.

[11] Nakanisi, K. (1965) IR spectra and structure of organic compounds. Mir (USSR), Moscow.

[12] JCPDS-Inter. Centre for Diffraction Data. PDF 00-039-1843, $\mathrm{C}_{6} \mathrm{H}_{12} \mathrm{~N}_{4}$.

[13] NIST Chemistry WebBook http://webbook.nist.gov/cgi/cbook.cgi?Formula=C6H12N4\&NoIon=on\&Units=SI\&cIR=on 